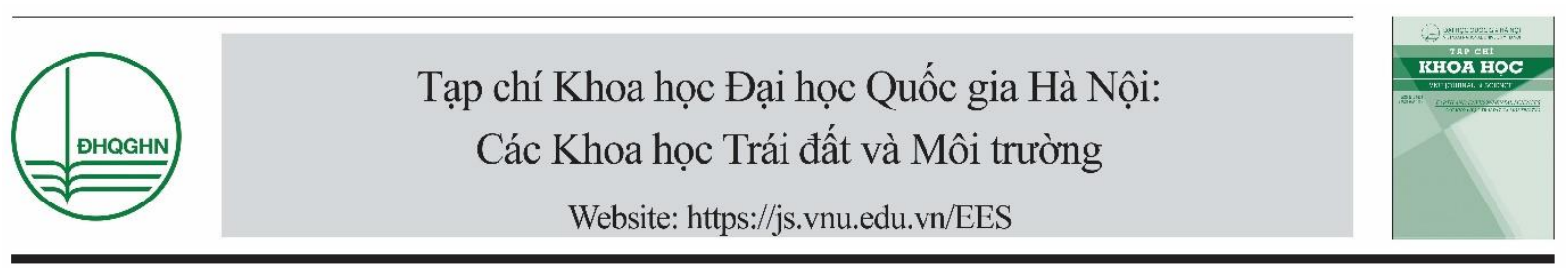

\title{
Nghiên cứu đánh giá hiện trạng sử dụng và chất lượng nước cấp sinh hoạt tại huyện Trảng Bàng, tỉnh Tây Ninh
}

\author{
Nguyễn Tri Quang Hưng ${ }^{1}$, Đinh Hùng Danh ${ }^{1}$, Thái Phương Vũ̃ ${ }^{2}$, \\ Nguyễn Minh Kỳ ${ }^{1, *}$, Huỳnh Ngọc Anh Tuấn ${ }^{1}$ \\ ${ }^{I}$ Trường Đại học Nông Lâm TP. Hồ Chí Minh, Việt Nam \\ ${ }^{2}$ Truờng Đại học Tài nguyên và Môi truờng TP. Hồ Chí Minh, Việt Nam \\ Nhận ngày 26 tháng 4 năm 2018 \\ Chỉnh sửa ngày 29 tháng 11 năm 2018; Chấp nhận đăng ngày 11 tháng 12 năm 2018
}

\begin{abstract}
Tóm tắt: Bài báo trình bày kết quả nghiên cứu đánh giá hiện trạng sử dụng và chất lượng nước cấp sinh hoạt huyện Trảng Bàng, tỉnh Tây Ninh. Liên quan đến tình hình sử dụng nước sạch của người dân huyện Trảng Bàng, tỷ lệ người dân sử dụng nước hợp vệ sinh khá thấp. Nghiên cứu tiến hành lấy mẫu, đánh giá chất lượng nước cấp đồng loạt tại các trạm cấp nước sạch nông thôn trên địa bàn các xã Phước Chỉ, Bình Thạnh và Phước Lưu. Kết quả phân tích thông số hóa lý chất lượng nước các trạm cấp nước sạch nông thôn huyện Trảng Bàng thể hiện các thông số nằm trong giới hạn cho phép của quy chuẩn nước sử dụng cho sinh hoạt QCVN02:2009/BYT và nước cấp sử dụng cho ăn uống QCVN01:2009/BYT. Tuy nhiên, một số mẫu với chỉ tiêu E.coli không đáp ứng điều kiện cấp nước cho sinh hoạt và ăn uống. Số liệu đánh giá tương quan giữa các thông số chất lượng nước nhìn chung với mối liên hệ chặt chẽ có ý nghĩa thống kê $(\mathrm{p}<0,05)$. Kết quả phân tích thành phần chính (PCA) trích xuất ba nhóm nhân tố chính (PCs) với chỉ số đại diện biến thiên (Eigenvalues) bằng 1,287 và tổng phương sai tích lũy tương ứng giải thích $86,426 \%$ tập dữ liệu. Từ đó cho thấy có thể sử dụng kết quả nghiên cứu nhằm đánh giá và diễn giải tình trạng chất lượng nước cấp sinh hoạt trên địa bàn huyện Trảng Bàng, tỉnh Tây Ninh.
\end{abstract}

Tù khóa: Chất lượng nước, Trảng Bàng, sinh hoạt, nước uống, cấp nước.

\section{Mở đầu}

Nước sạch là nguồn tài nguyên thiên nhiên quan trọng [1] và là nhu cầu thiết yếu trong cuộc sống của mỗi người dân [2]. Nguồn nước sử dụng cho các mục đích sinh hoạt, đặc biệt cho ăn uống rất quan trọng bởi lẽ có vai trò và những tác động trực tiếp lên sức khỏe con người [3-6]. Hàm lượng các thông số chất lượng nước quá thấp hoặc quá cao đều gây ra những ảnh hưởng đến sức khỏe. Các kết quả ước tính trên Trái đất có

\footnotetext{
*Tác giả liên hệ. ĐT.: 84-916121204.

Email: nmky@hcmuaf.edu.vn

https://doi.org/10.25073/2588-1094/vnuees.4251
} 
khoảng 1,4 tỷ km³ nước nhưng nguồn nước ngọt, có khả năng sử dụng ăn uống và sinh hoạt chỉ chiếm lượng nhỏ, tương ứng 3\% [7].Theo thống kê của Tổ chức Y tế thế giới và Quỹ nhi đồng Liên hiệp quốc (WHO-UNICEF, 2015) hiện có khoảng 663 triệu người không được tiếp cận các nguồn nước uống [8]. Vấn đề phổ biến ảnh hưởng đến chất lượng nguồn nước cấp ở các nước đang phát triển thường do hệ thống phân phối, cung cấp nước [9].

Xét riêng bối cảnh tỉnh Tây Ninh, Trảng Bàng vốn được đánh giá là huyệnthuộc vùng nông thôn có các điều kiện kinh tế- xã hội khó khăn [10]. Quá trình khảo sát thực tế cho thấy các công trình được quy hoạch trước đây chủ yếu nhỏ lẻ và không đáp ứng yêu cầu về chất lượng, công suất cũng nhưquản lý vận hành.Việc thực hiện nhiệm vụ cung cấp nước sạch và vệ sinh môi trường nông thôn càng trở nên thách thức. Để có cơ sở đầu tư, nâng cấp hay đề xuất giải pháp để nâng cao chất lượng cung cấp nước sạch nông thôn, đáp ứng nhu cầu sử dụng nước sinh hoạt cho người dân nông thôn huyện Trảng Bàng cần những nghiên cứu hiện trạng sử dụng và chất lượng nước. Tuy nhiên, để đánh giá chính xác và toàn diện thực trạng chất lượng nước nói chung và nước cấp nói riêng đòi hỏi áp dụng các công cụ thích hợp. Việc đánh giá chất lượng nước áp dụng kỹ thuật như phân tích thống kê đa biến ngày càng phổ biến [11-13]. Đây là công cụ hữu ích cho quá trình phân nhóm, xem xét giải thích các chỉ tiêu chất lượng nước [14-16]. Xuất phát từ đó, công trình"Nghiên cứu đánh giá hiện trạng sử dụng và chất luợng nước cấp sinh hoạt huyện Trảng Bàng, tỉnh Tây Ninh" được thực hiện với mong muốn góp phần đánh giá đúng hiện trạng cấp nước sạch và làm cơ sở đề xuất giải pháp quản lý thích hợp.

\section{Phương pháp nghiên cứu}

\section{1. Đối tượng nghiên cứu}

* Phạm vi nghiên cứu: Các xã Phước Chỉ, Bình Thạnh và Phước Lưu, huyện Trảng Bàng, tỉnh Tây Ninh.

* Đối tượng nghiên cứu: Các thông số chất lượng nước, gồm: Màu sắc, mùi vị, $\mathrm{pH}$, độ đục, amoni, sắt tổng, chỉ số pecmanganat, độ cứng, clorua, florua, asen, coliform, E.coli.

\subsection{Vị trí lấy mẫu}

Nghiên cứu tiến hành lấy mẫu nước cấp tại chín trạm cấp nước sạch nông thôn trên địa bàn các xã Phước Chỉ, Bình Thạnh và Phước Lưu, huyện Trảng Bàng. Thông tin vị trí các điểm lấy mẫu phân tích, đánh giá chất lượng nước được mô tả ở Bảng 1.

Bảng 1 . Thông tin mẫu quan trắc chất lượng nước cấp

\begin{tabular}{lllll}
\hline TT & Ký hiệu & Tên trạm & Địa chỉ & Điều kiện lấy mẫu \\
\hline 1 & S1 & Phước Bình & Âp Phước Bình, Phước Chỉ & \\
2 & S2 & Phước Hòa & Ấp Phước Hòa, Phước Chỉ & \\
3 & S3 & Phước Mỹ & Ấp Phước Mỹ, Phước Chỉ & Vận hành ổn định, \\
4 & S4 & Phước Hưng 2 & Ấp Phước Hưng 2, Phước Chỉ & giữa các thời kỳ rửa \\
5 & S5 & Phước Thành 1 & Ấp Phước Thành 1, Phước Lưu & lọ̣, đảm bảo các \\
6 & S6 & Phước Thành 2 & Ấp Phước Thành 2, Phước Lưu & điêu kiện vệ sinh. \\
7 & S7 & Bình Quới & Ấp Bình Quới, Bình Thạnh & \\
8 & S8 & Bình Hòa 1 & Ấp Bình Hòa 1, Bình Thạnh & \\
9 & S9 & Bình Hòa 2 & Âp Bình Hòa 2, Bình Thạnh & \\
\hline
\end{tabular}

\subsection{Phưong pháp lấy mẫu và phân tích}

Quy trình lấy mẫu tuân thủ theo hướng dẫn lấy mẫu nước TCVN 6663-11:2011. Mẫu được bảo quản và vận chuyển theo TCVN 66633:2008. Quá trình phân tích mẫu được thực hiện lặp lại 03 lần. Các phương pháp phân tích chất lượng nước trình bày tóm lược ở Bảng 2 . 
12 N.T.Q. Hung và nnk. / Tạp chí Khoa học ĐHQGHN: Các Khoa học Trái đất và Môi truờng, Tập 34, Số 4 (2018) 10-21

Bảng 2. Các phương pháp phân tích chất lượng nước

\begin{tabular}{llll}
\hline TT & Thông số & Đơn vị & Phương pháp phân tích \\
\hline 1 & Màu sắc & TCU & SMEWW 2120 C:2002 \\
2 & Mùi vị & - & SMEWW 2150 B:2002 \\
3 & $\mathrm{pH}$ & - & TCVN 6492:2011 \\
4 & Độ đục & $\mathrm{NTU}$ & SMEWW 2130 B:2002 \\
5 & Amoni & $\mathrm{mg} / \mathrm{L}$ & SMEWW 4500-NH ${ }_{3}^{\mathrm{F}: 2012}$ \\
6 & Sắt tổng & $\mathrm{mg} / \mathrm{L}$ & TCVN 6177:1996 \\
7 & Pecmanganat & $\mathrm{mg} / \mathrm{L}$ & TCVN 6186:1996 \\
8 & Độ cứng $(\mathrm{CaCO})$ & $\mathrm{mg} / \mathrm{L}$ & TCVN 6224:1996 \\
9 & Clorua & $\mathrm{mg} / \mathrm{L}$ & TCVN 6194:1996 \\
10 & Florua & $\mathrm{mg} / \mathrm{L}$ & SMEWW 4500 F.D:2012 \\
11 & Asen & $\mathrm{mg} / \mathrm{L}$ & TCVN 6626:2000 \\
12 & Coliform & $\mathrm{MPN} / 100 \mathrm{~mL}$ & TCVN 6187-2:1996 \\
13 & E.coli & $\mathrm{MPN} / 100 \mathrm{~mL}$ & TCVN 6187-2:1996 \\
\hline
\end{tabular}

2.4. Phưong pháp so sánh, đánh giá kết quả và xử lý số liệu

Để đánh giá các chỉ tiêu chất lượng nước, nghiên cứu so sánh với Quy chuẩn kỹ thuật quốc gia QCVN 02:2009/BYT về chất lượng nước sinh hoạt và Quy chuẩn kỹ thuật Quốc gia QCVN 01: 2009/BYT về chất lượng nước ăn uống do Bộ Y tế ban hành. Đồng thời, nghiên cứu tiến hành phân tích kiểm định tương quan Pearsonvà phân tích thành phần chính (PCA) với mức ý nghĩa $\alpha=0,05$. Các số liệu được thống kê xử lý bằng các phần mềm $\mathrm{M}$.Excel và SPSS.

\section{Kết quả nghiên cứu và bàn luận}

\subsection{Hiện trạng cấp và sủ dụng nước sinh hoạt tại huyện Trảng Bàng}

Bảng 3 tổng hợp các công trình cấp nước tập trung có mạng lưới đường ống phân phối tới hộ gia đình tại 3 xã Phước Chỉ, Bình Thạnh và Phước Lưu.

Về thực trạng quy trình công nghệ xử lý nước áp dụng cho các công trình trên địa bàn huyện như Hình 1.
Bảng 3. Tổng hợp công trình cấp nước sinh hoạt huyện Trảng Bàng

\begin{tabular}{llll}
\hline TT & $\begin{array}{l}\text { Địa phương } \\
\text { (xã) }\end{array}$ & $\begin{array}{l}\text { Số } \\
\text { trạm }\end{array}$ & $\begin{array}{l}\text { Tổng công } \\
\text { suất } \\
\left(\mathrm{m}^{3} / \text { ngày }\right)\end{array}$ \\
\hline 1 & Bình Thạnh & 3 & 300 \\
2 & Phước Chỉ & 7 & 555 \\
3 & Phước Lưu & 2 & 200 \\
\hline Tổng & & 12 & 1.055 \\
\hline
\end{tabular}

Nước ngầm từ các giếng khoan có độ sâu trung bình từ 4 đến $11 \mathrm{~m}$ được bơm, theo đường ống thu nước đưa lên giàn mưa. Giàn mưa là công trình làm thoáng tự nhiên, có chức năng làm giàu oxy cho nước và loại khí $\mathrm{CO}_{2}$ có trong nước để tạo điều kiện cho $\mathrm{Fe}^{2+}$ oxy hóa thành $\mathrm{Fe}^{3+}$. Sau đó quá trình thủy phân tạo thành những hợp chất ít $\tan \mathrm{Fe}(\mathrm{OH})_{3}$ đồng thời $\mathrm{pH}$ được nâng lên. Nước tiếp tục qua bể lắng tiếp xúc với chức năng chính lưu nước để cho $\mathrm{Fe}^{2+}$ tiếp xúc với oxy không khí, tạo điều kiện quá trình oxy hóa và thủy phân diễn ra hoàn toàn, đồng thời giữ một phần bông cặn nặng trước khi qua bể lọc. Sau khi qua bể lắng tiếp xúc, nước đi vào bể lọc, qua lớp vật liệu lọc bằng cát thạch anh, than hoạt tính, lớp sỏi đỡ trước khi vào hệ thống thu nước trong và được đưa về bể chứa nước sạch. Sau cùng, 
châm chlorine khử trùng rồi bơm lên đài nước để phân phối cấp đến các hộ dân.

Liên quan đến tình hình sử dụng nước sạch của người dân huyện Trảng Bàng được tổng hợp ở Bảng 4-5. Nhìn chung, tỷ lệ người dân tại 3 xã có trạm cấp nước đã sử dụng nước hợp vệ sinh còn thấp. Trong đó, cao nhất ở xã Bình Thạnh với $62,4 \%$, thấp nhất là $26,8 \%$ tại xã Phước Chỉ.Tỷ lệ hộ nghèo huyện Trảng Bàng sử dụng nước hợp vệ sinh chỉ chiếm 17,1-29,7\%.

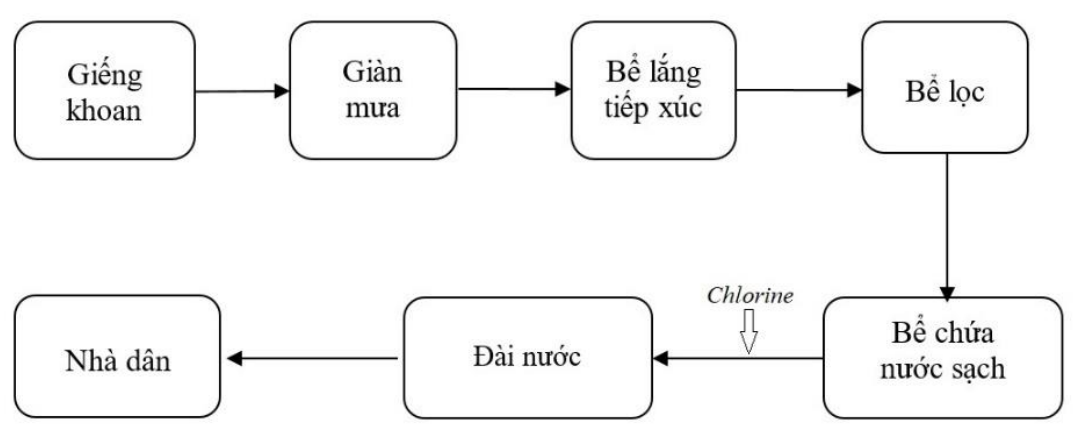

Hình 1. Quy trình xử lý cấp nước huyện Trảng Bàng.

Bảng 4. Thực trạng sử dụng nước cấp hợp vệ sinh ở địa phương

\begin{tabular}{llllllll}
\hline TT & $\begin{array}{l}\text { Địa phương } \\
\text { (xã) }\end{array}$ & $\begin{array}{l}\text { Số dân } \\
\text { (người) }\end{array}$ & $\begin{array}{l}\text { Số dân được } \\
\text { cấp nước HVS } \\
\text { (người) }\end{array}$ & $\begin{array}{l}\text { Tỷ lệ sử } \\
\text { dụng nước } \\
\text { HVS }(\%)\end{array}$ & $\begin{array}{l}\text { Người } \\
\text { nghèo } \\
\text { (người) }\end{array}$ & $\begin{array}{l}\text { Số người } \\
\text { nghèo được } \\
\text { cấp nước } \\
\text { HVS }\end{array}$ & $\begin{array}{l}\text { Tỷ lệ người } \\
\text { nghèo sử dụng } \\
\text { nước HVS } \\
(\%)\end{array}$ \\
\hline 1 & Phước Chỉ & 10.671 & 2.865 & 26,8 & 392 & 67 & 17,1 \\
2 & Phước Lưu & 6.049 & 2.814 & 46,5 & 458 & 128 & 27,9 \\
3 & Bình Thạnh & 11.288 & 7.047 & 62,4 & 74 & 22 & 29,7 \\
\hline \multicolumn{2}{l}{ Tổng } & 28.008 & 12.726 & 45,4 & 924 & 217 & 23,5 \\
\hline
\end{tabular}

Chú thich: HVS_Hơp vệsinh

Bảng 5. Thực trạng cấp nước tại các trường học và trạm y tế

\begin{tabular}{llllllll}
\hline & \multirow{2}{*}{$\begin{array}{l}\text { Địa phương } \\
\text { (xã) }\end{array}$} & Số trường & $\begin{array}{l}\text { Số lượng có } \\
\text { nước HVS }\end{array}$ & Tỷ lệ, \% & Số trạm & $\begin{array}{l}\text { Số lượng có } \\
\text { nước HVS }\end{array}$ & Tỷ lệ, \% \\
\cline { 3 - 7 } & Phước Chỉ & 11 & 2 & 18,2 & 1 & 1 & 100 \\
2 & Phước Lưu & 5 & 1 & 20,0 & 1 & 1 & 100 \\
3 & Bình Thạnh & 4 & 4 & 100 & 1 & 1 & 100 \\
\hline
\end{tabular}

Hiện tại, số trường học có nước hợp vệ sinh để sử dụng chiếm tỷ lệ thấp khoảng 18,2-20\% ở xã Phước Chỉ và Phước Lưu. Riêng xã Bình Thạnh toàn bộ 4 trường học đã có nước hợp vệ sinh chiếm tỷ lệ $100 \%$.Đối với trạm y tế của 3 xã
Chú thích: HVS_Hơp vệ sinh

đã được sử dụng nước hợp vệ sinh chiếm tỷ lệ $100 \%$. Nguồn nước sử dụng được phân phối từ các trạm cấp nước sạch.Đối với 13/20 trường học chưa có nước sạch sử dụng có nguy cơ ảnh hưởng đến sức khỏe học sinh, gây khó khăn cho 
việc phát triển toàn diện của trẻ. Các độc tố trong nguồn nước cấp bị nhiễm bẩn còn là nguyên nhân gây ra rủi ro bệnh tật nguy hiểm như ung thư dạ dày [17].

Do nguồn nước mặt và nước ngầm tầng nông bị nhiễm phèn nên các hộ dân sử dụng nguồn nước không được đảm bảo vệ sinh.Các số liệu ở trên cho thấy, trên địa bàn 3 xã Phước Chỉ, Phước Lưu, Bình Thạnh vẫn còn $54,6 \%$ người dân chưa được sử dụng nước sạch hợp vệ sinh.

\section{2. Đánh giá thực trạng chất lương nước cấp} sinh hoạt huyện Trảng Bàng

\subsubsection{Chỉ tiêu màu sắc, mùi vị, độ đục và $p H$}

Kết quả phân tích thông số độ đục cho thấy có 3/9 trạm cấp nước sạch nông thôn tại huyện Trảng Bàng vượt giới hạn cho phép cấp nước cho ăn uống theo QCVN01:2009/BYT, bao gồm các trạm Phước Mỹ, Phước Thành 1 và Phước Thành 2. Đặc biệt, tại trạm Phước Mỹ, độ đục của nước cấp cao hơn quy định cho mục đích cấp nước sinh hoạt theo QCVN 02: 2009/BYT.

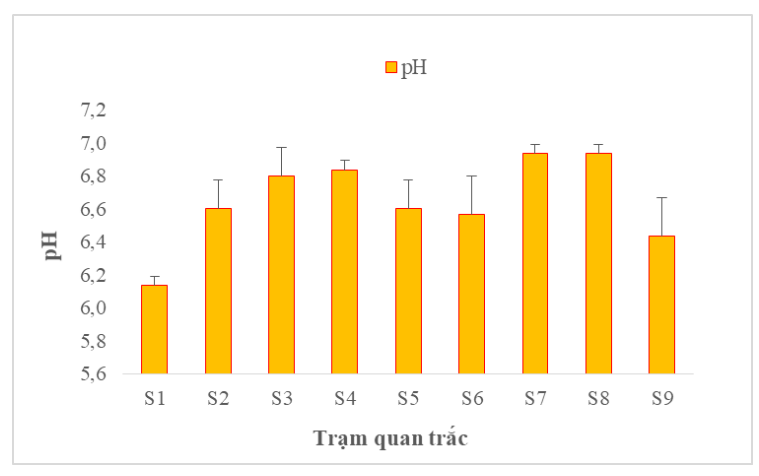

Hình 2. Giá trị pH các trạm quan trắc huyện Trảng Bàng.

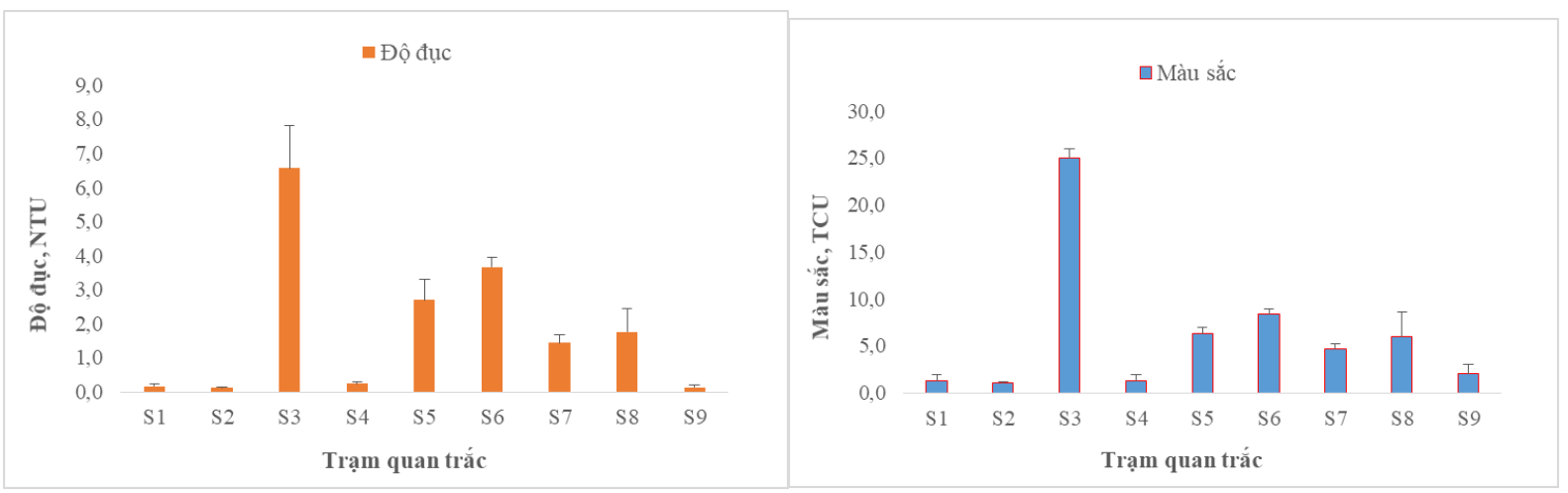

Hình 3. Màu sắc và độ đục các trạm quan trắc huyện Trảng Bàng.

Thông số pH các trạm cấp nước sạch nông thôn trên địa bàn huyện Trảng Bàng đều nằm trong giới hạn cho phép của quy chuẩn nước cấp cho ăn uống và sinh hoạt do Bộ y tế ban hành. Tuy nhiên, một số giá trị thông số pH thấp ở các trạm Phước Bình $(\mathrm{pH}=6,1 \pm 0,06)$ và Bình Hòa 2 $(\mathrm{pH}=6,4 \pm 0,23)$. Vì vậy, các trạm cấp nước cần phải tăng cường công tác theo dõi giá trị $\mathrm{pH}$ thường xuyên để có hành động điều chỉnh kịp thời. Kết quả phân tích cho thấy nước tại các trạm cấp nước sạch nông thôn của huyện Trảng Bàng không có mùi vị bất thường. Chỉ số màu sắc cũng nằm trong giới hạn cho phép của QCVN 01:2009/BYT. Ngoại trừ tại trạm cấp nước Phước Mỹ, chỉ tiêu màu sắc đạt $25 \pm 1,00$ TCU, cao hơn giới hạn cho phép 10 TCU.

\subsubsection{Kết quả thông số hóa lý sinh nguồn} nước cấp

Kết quả phân tích thông số hóa lýsinh chất lượng nước quan trọng các trạm cấp nước sạch nông thôn huyện Trảng Bàng được tổng hợp, thể hiện chi tiết ở Bảng 6 và các Hình 4-5. Nhìn chung, các thông số chất lượng nước nằm trong các khoảng giới hạn cho phép cấp cho mục đích sinh hoạt QCVN02:2009/BYT và ăn uống QCVN01:2009/BYT của Bộ Y tế. 
Bảng 6. Kết quả phân tích các thông số hóa lý sinh nguồn nước cấp

\begin{tabular}{|c|c|c|c|c|c|c|}
\hline Thông số & $\begin{array}{l}\text { Màu sắc, } \\
\text { TCU }\end{array}$ & Độ đục, NTU & $\mathrm{pH}$ & $\mathrm{NH}_{4}^{+}, \mathrm{mg} / \mathrm{L}$ & $\mathrm{Fe}, \mathrm{mg} / \mathrm{L}$ & $\begin{array}{l}\text { Asen, } \\
\mathrm{mg} / \mathrm{L}\end{array}$ \\
\hline Trạm & $\mathrm{n}=3$ & $\mathrm{n}=3$ & $\mathrm{n}=3$ & $\mathrm{n}=3$ & $\mathrm{n}=3$ & $\mathrm{n}=3$ \\
\hline $\mathrm{S} 1$ & $1,3 \pm 0,58$ & $0,2 \pm 0,06$ & $6,1 \pm 0,06$ & $0,010 \pm 0,017$ & $0,07 \pm 0,012$ & $<0,001$ \\
\hline $\mathrm{S} 2$ & $1,1 \pm 0,12$ & $0,1 \pm 0,02$ & $6,6 \pm 0,17$ & $0,017 \pm 0,015$ & $0,04 \pm 0,012$ & $<0,001$ \\
\hline $\mathrm{S} 3$ & $25,0 \pm 1,00$ & $6,6 \pm 1,25$ & $6,8 \pm 0,17$ & $0,050 \pm 0,006$ & $0,29 \pm 0,006$ & $<0,001$ \\
\hline S4 & $1,3 \pm 0,58$ & $0,2 \pm 0,06$ & $6,8 \pm 0,06$ & $0,023 \pm 0,006$ & $0,12 \pm 0,006$ & $<0,001$ \\
\hline S5 & $6,3 \pm 0,58$ & $2,7 \pm 0,61$ & $6,6 \pm 0,17$ & $0,047 \pm 0,012$ & $0,17 \pm 0,031$ & $<0,001$ \\
\hline S6 & $8,3 \pm 0,58$ & $3,7 \pm 0,29$ & $6,6 \pm 0,23$ & $0,137 \pm 0,012$ & $0,19 \pm 0,006$ & $<0,001$ \\
\hline S7 & $4,7 \pm 0,58$ & $1,4 \pm 0,23$ & $6,9 \pm 0,06$ & $0,043 \pm 0,023$ & $0,13 \pm 0,006$ & $<0,001$ \\
\hline S8 & $6,0 \pm 2,65$ & $1,8 \pm 0,67$ & $6,9 \pm 0,06$ & $0,027 \pm 0,012$ & $0,14 \pm 0,053$ & $<0,001$ \\
\hline S9 & $2,0 \pm 1,00$ & $0,1 \pm 0,06$ & $6,4 \pm 0,23$ & $0,023 \pm 0,006$ & $0,03 \pm 0,006$ & $<0,001$ \\
\hline $\begin{array}{l}\text { QCVN } \\
02: 2009 / \mathrm{BYT}\end{array}$ & 15 & 5 & $6,0-8,5$ & 3 & 0,5 & 0,01 \\
\hline $\begin{array}{l}\text { QCVN } \\
01: 2009 / \mathrm{BYT}\end{array}$ & 15 & 2 & $6,5-8,5$ & 3 & 0,3 & 0,01 \\
\hline
\end{tabular}

Bảng 6. Kết quả phân tích các thông số hóa lý sinh nguồn nước cấp (tt)

\begin{tabular}{|c|c|c|c|c|c|c|}
\hline Thông số & $\begin{array}{l}\text { Pecmanganat, } \\
\mathrm{mg} / \mathrm{L}\end{array}$ & $\begin{array}{l}\text { Độ cứng, } \\
\text { mg/L }\end{array}$ & Clo, mg/L & Flo, mg/L & $\begin{array}{l}\text { Coliform, } \\
\text { MPN/100mL }\end{array}$ & $\begin{array}{l}\text { E.coli, } \\
\text { MPN/100mL }\end{array}$ \\
\hline Trạm & $\mathrm{n}=3$ & $\mathrm{n}=3$ & $\mathrm{n}=3$ & $\mathrm{n}=3$ & $\mathrm{n}=3$ & $n=3$ \\
\hline $\mathrm{S} 1$ & $0,33 \pm 0,058$ & $17,9 \pm 0,06$ & $10,07 \pm 0,924$ & $0,01 \pm 0,006$ & 0,0 & 0,0 \\
\hline $\mathrm{S} 2$ & $0,17 \pm 0,058$ & $11,4 \pm 0,06$ & $7,27 \pm 0,635$ & $0,01 \pm 0,006$ & 0,0 & 0,0 \\
\hline $\mathrm{S} 3$ & $2,63 \pm 0,058$ & $34,7 \pm 8,89$ & $5,00 \pm 0,173$ & $0,06 \pm 0,006$ & $109,0 \pm 18,520$ & $9,7 \pm 1,155$ \\
\hline $\mathrm{S} 4$ & $0,87 \pm 0,115$ & $15,8 \pm 0,81$ & $4,90 \pm 0,693$ & $0,02 \pm 0,012$ & 0,0 & 0,0 \\
\hline S5 & $2,33 \pm 3,175$ & $86,1 \pm 10,33$ & $9,70 \pm 0,173$ & $0,06 \pm 0,012$ & $77,0 \pm 2,646$ & 0,0 \\
\hline S6 & $0,53 \pm 0,115$ & $43,4 \pm 0,06$ & $6,73 \pm 0,058$ & $0,06 \pm 0,006$ & $144,3 \pm 5,132$ & 0,0 \\
\hline S7 & $0,43 \pm 0,058$ & $21,8 \pm 1,50$ & $9,23 \pm 0,058$ & $0,01 \pm 0,006$ & 0,0 & 0,0 \\
\hline S8 & $0,87 \pm 0,115$ & $143,9 \pm 19,86$ & $79,47 \pm 3,002$ & $0,01 \pm 0,006$ & $114,3 \pm 14,364$ & 0,0 \\
\hline S9 & $0,77 \pm 0,115$ & $44,7 \pm 5,77$ & $29,53 \pm 0,058$ & $0,02 \pm 0,012$ & 0,0 & 0,0 \\
\hline $\begin{array}{l}\text { QCVN } \\
02: 2009 / \mathrm{BYT}\end{array}$ & 4 & 350 & 300 & 1,5 & 50 & 0 \\
\hline $\begin{array}{l}\text { QCVN } \\
01: 2009 / \mathrm{BYT}\end{array}$ & 2 & 300 & 250 & 1,5 & 0 & 0 \\
\hline
\end{tabular}

Hàm lượng amoni dao động trong khoảng 0,01 đến $0,15 \mathrm{mg} / \mathrm{L}$, thấp hơn nhiều lần so với quy chuẩn cấp nước sinh hoạt và ăn uống (3 $\mathrm{mg} / \mathrm{L}$ ). Hàm lượng sắt tổng nhỏ hơn ngưỡng cho phép và biến thiên từ 0,03 đến $0,30 \mathrm{mg} / \mathrm{L}$. Chỉ tiêu pecmanganat, độ cứng, clorua và florua khá thấp (Bảng 6). Đối với hàm lượng asen không phát hiện thấy trong các mẫu phân tích. Về cơ bản cho thấy sự ổn định và mức độ an toàn đối với mục đích sử dụng nước cấp cho sinh hoạt, ăn uống. 


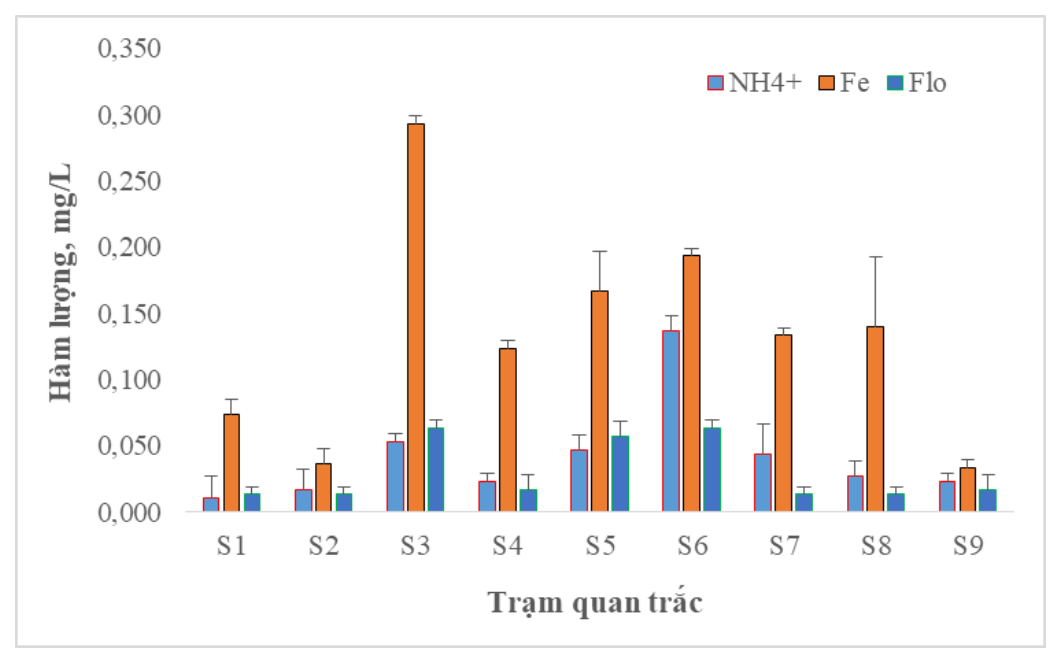

Hình 4. Thông số hóa lý chất lượng nước các trạm quan trắc.

Đối với các chỉ tiêu vi sinh coliform và E.coli, kết quả phân tích thông số coliform tại các trạm cấp nước nông thôn của huyện Trảng Bàng cho thấy chất lượng nước hầu hết các trạm không thể dùng cho mục tiêu cấp nước ăn uống. So sánh với quy chuẩn cấp nước cho sinh hoạt QCVN 02:2009/BYT, có 4 trạm với trị số coliform trung bình bao gồm Phước Mỹ
(109,0 $\pm 18,520$ MPN/100ml), Phước Thành 1 $(77,0 \pm 2,646 \mathrm{MPN} / 100 \mathrm{ml})$, Phước Thành 2 $(144,3 \pm 5,132 \mathrm{MPN} / 100 \mathrm{ml})$ và Bình Hòa 1 $(114,3 \pm 14,364$ MPN/100ml) không đạt tiêu chuẩn cấp nước sử dụng.

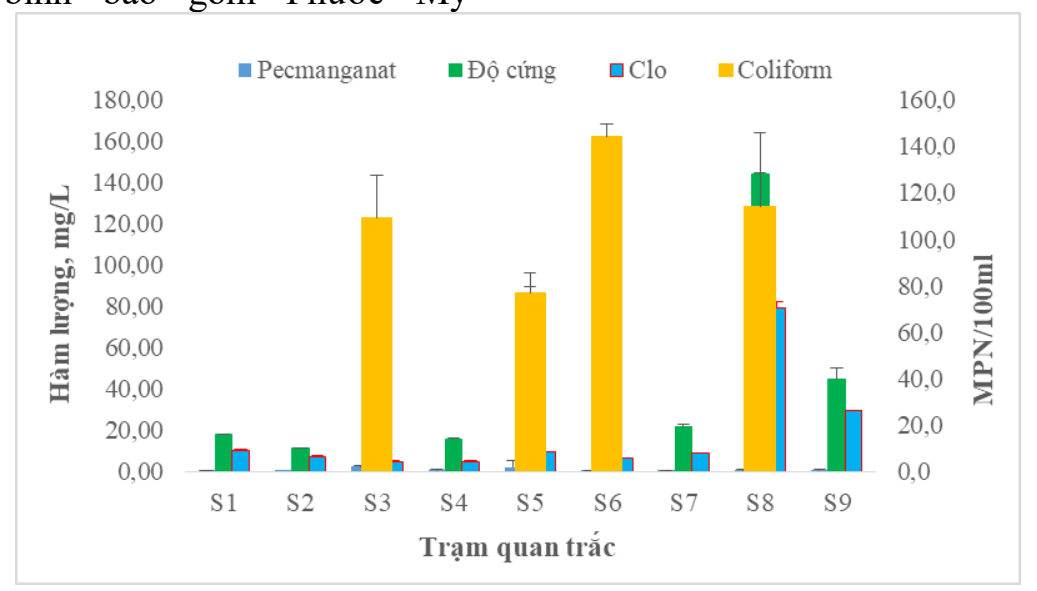

Hình 5. Chỉ tiêu hóa sinh chất lượng nước các trạm quan trắc.

Phân tích chỉ tiêu E.coli chỉ ra phần lớn kết quả các giá trị nằm trong ngưỡng giới hạn cho phép đối với chất lượng nước cấp cho ăn uống và sinh hoạt. Riêng mẫu nước cấp tại trạm Phước

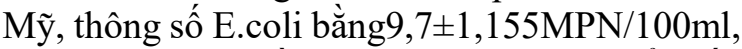
do đó không đủ điều kiện đáp ứng tiêu chuẩn cấp nước cho các mục đích sinh hoạt và ăn uống.
Trong khi, sự nhiễm bẩn E.coli ở nguồn nước vốn được đánh giá và xem xét với các mức độ nghiêm trọng [18]. Do đó, cần nghiên cứu áp dụng các giải pháp lọc màng hiện đại như vi lọc, siêu lọc đạt hiệu quả cao trong việc loại bỏ hàm lượng các chất nhiễm bẩn cũng như yếu tố mầm bệnh [19]. Nhìn chung, khi xét riêng chỉ tiêu vi 
sinh, chất lượng nước tại 4/9 trạm cấp nước sạch nông thôn trên địa bàn huyện Trảng Bàng không đủ điều kiện cấp nước sinh hoạt. Từ đó cần phải xem xét chặt chẽ hơn nữa quá trình khử trùng tại các trạm cấp nước sinh hoạttrước khi phân phối đến các hộ dân.

Như vậy, đánh giá chung về chất lượng nước tại các trạm lấy mẫu phân tích trên địa bàn huyện Trảng Bàng chỉ ra rằng:(i)_Tình trạng tại trạm cấp nước Phước Mỹ cho thấy sự nghiêm trọng nhất. Cụ thể, cả 4 chỉ tiêu quan trọng như độ màu ( $25 \pm 1,00$ TCU so với quy chuẩn $15 \mathrm{TCU})$, độ đục $(6,6 \pm 1,25 \mathrm{NTU}$ so với quy chuẩn $2 \mathrm{NTU})$, hàm lượng coliform $(109,0 \pm 18,520 \mathrm{MPN} / 100 \mathrm{ml}$ so với quy chuẩn $0 \mathrm{MPN} / 100 \mathrm{ml}$ ) và E.coli $(9,7 \pm 1,155 \mathrm{MPN} / 100 \mathrm{ml}$ so với quy chuẩn 0 MPN/100ml) đều vượt ngưỡng giới hạn cho phép của QCVN 01:2009/BYT - Quy chuẩn kỹ thuật quốc gia về chất lượng nước ăn uống. (ii)_Tại các trạm Phước Thành 1 và Phước
Thành 2 , chất lượng nước cũng không được tốt khi 2 chỉ tiêu: độ đục (lần lượt $2,7 \pm 0,61$ và $3,7 \pm 0,29 \mathrm{NTU}$ so với quy chuẩn $2 \mathrm{NTU}$ ), hàm

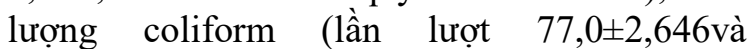
$144,3 \pm 5,132 \mathrm{MPN} / 100 \mathrm{ml}$ so với quy chuẩn 0 MPN/100ml) vượt quá so với giới hạn cho phép của QCVN 01:2009/BYT.

3.3. Phân tích thống kê đa biến đánh giá các thông số chất luợng nước

Nhằm đánh giá, phân nhóm thông số chỉ tiêu chất lượng nước, thủ tục phân tích tương quan và PCA được thực hiện. Kết quả đánh giá tương quan giữa các thông số chất lượng nước được trình bày tổng hợp ở Bảng 7 . Nhìn chung, phần lớn các thông số chất lượng nước có mối liên hệ chặt chẽ có ý nghĩa thống kê $(\mathrm{p}<0,05)$. Phân tích tương quan có thể giải quyết việc quản lý chất lượng nước một cách hiệu quả [20].

Bảng 7. Kết quả phân tích tương quan giữa các chỉ tiêu chất lượng nước

\begin{tabular}{lllllllllll}
\hline & Màu sắc & Độ đục & $\mathrm{pH}$ & $\mathrm{NH}_{4}^{+}$ & $\mathrm{Fe}$ & Pecmanganat & Độ cứng & Clo & Flo & Coliform \\
\hline Màu sắc & 1 & $0,932(* *)$ & 0,276 & 0,360 & $0,857(* *)$ & $0,888(* *)$ & 0,113 & $-0,106$ & $0,682(* *)$ & $0,636(* *)$ \\
Độ đục & $0,932(* *)$ & 1 & 0,316 & $0,549(* *)$ & $0,921(* *)$ & $0,754(* *)$ & 0,162 & $-0,133$ & $0,788(* *)$ & $0,742(* *)$ \\
pH & 0,276 & 0,316 & 1 & 0,125 & $0,398(*)$ & 0,290 & 0,269 & 0,251 & 0,006 & 0,220 \\
$\mathrm{NH}_{4}^{+}$ & 0,360 & $0,549(* *)$ & 0,125 & 1 & $0,532(* *)$ & 0,097 & 0,048 & $-0,210$ & $0,707(* *)$ & $0,685(* *)$ \\
Fe & $0,857(* *)$ & $0,921(* *)$ & $0,398(*)$ & $0,532(* *)$ & 1 & $0,737(* *)$ & 0,162 & $-0,137$ & $0,732(* *)$ & $0,712(* *)$ \\
Pecmanganat & $0,888(* *)$ & $0,754(* *)$ & 0,290 & 0,097 & $0,737(* *)$ & 1 & 0,056 & $-0,014$ & $0,469(*)$ & $0,415(*)$ \\
Độ cứng & 0,113 & 0,162 & 0,269 & 0,048 & 0,162 & 0,056 & 1 & $0,837(* *)$ & 0,105 \\
Clo & $-0,106$ & $-0,133$ & 0,251 & $-0,210$ & $-0,137$ & $-0,014$ & $0,837(* *)$ & 1 & $0,592(* *)$ \\
Flo & $0,682(* *)$ & $0,788(* *)$ & 0,006 & $0,707(* *)$ & $0,732(* *)$ & $0,469(*)$ & 0,105 & $-0,329$ & 1 \\
Coliform & $0,636(* *)$ & $0,742(* *)$ & 0,220 & $0,685(* *)$ & $0,712(* *)$ & $0,415(*)$ & $0,592(* *)$ & 0,284 & $0,715(* *)$ & 1 \\
\hline
\end{tabular}

** Tưong quan múc ý nghĩa 0,01. * Tưong quan múc ý nghĩa 0,05.

Trong đó, màu sắc thể hiện tương quan cao với các yếu tố như độ đục $(\mathrm{r}=0,932)$, sắt $(\mathrm{r}=0,857)$, flo $(\mathrm{r}=0,682)$ và coliform $(\mathrm{r}=0,636)$. Độ đục cũng cho thấy sự gắn kết với các yếu tố như $\mathrm{NH}_{4}{ }^{+}$, sắt, pecmanganat, flo cũng như hàm lượng vi sinh coliform. Trong khi, giá trị $\mathrm{pH}$ chỉ thể hiện sự tác động với hàm lượng sắt trong nước với hệ số tương quan thấp $\mathrm{r}=0,398$ $(\mathrm{p}<0,05)$. Hàm lượng $\mathrm{NH}_{4}{ }^{+}$tương quan khá tốt với yếu tố độ đục, sắt, flo và coliform ứng với hệ số tương quan lần lượt 0,$549 ; 0,532 ; 0,707$ và $0,685(\mathrm{p}<0,01)$. Sự có mặt hàm lượng amoni và coliform trong nguồn nước luôn là mối quan tâm hàng đầu đến vấn đề an toàn sức khỏe $[21,22]$.

Thành phần sắt trong môi trường nước được thể hiện bởi hệ số tương quan cao với màu sắc, độ đục, $\mathrm{pH}, \mathrm{NH}_{4}{ }^{+}$, flo, coliform, pecmanganat. Riêng độ cứng chỉ thể hiện tương quan với clo 
và coliform lần lượt hệ số 0,837 và 0,592 $(\mathrm{p}<0,05)$. Đối với chỉ tiêu coliform cho thấy mức độ tương quan và ảnh hưởng với hầu hết các thông số hóa lý của mẫu nước nghiên cứu $(\mathrm{p}<0,01)$. Như vậy, từ những kết quả phân tích cho thấy sự liên hệ và tương tác qua lại giữa các chỉ tiêu chất lượng nước. Qua đó, có thể sử dụng nhằm đánh giá và diễn giải tình trạng chất lượng nước trong mối liên hệ giữa các thông số với nhau.

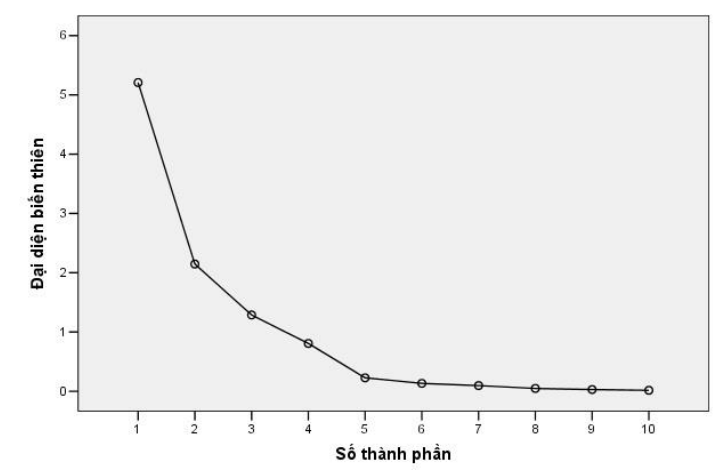

Hình 6. Kết quả chỉ số đại diện biến thiên.

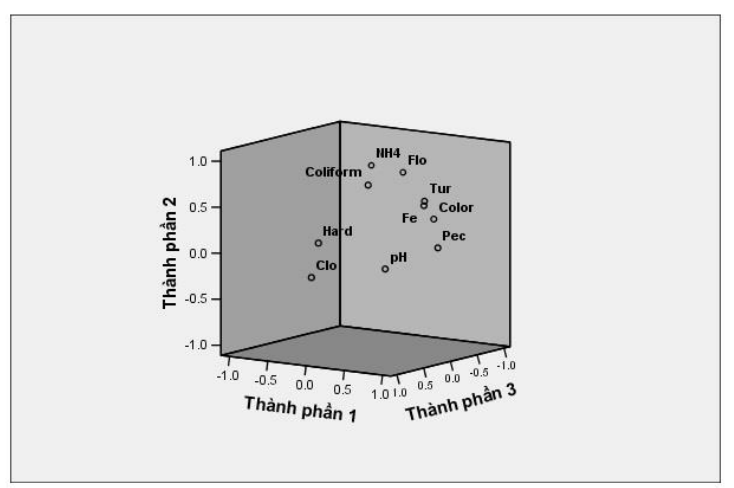

Hình 7. Kết quả các thành phần chính PCs.

Bên cạnh đó, PCA là công cụ sử dụng rộng rãi để nghiên cứu giải thích nguồn tác động đến tình trang chất lượng nước $[23,24]$. Liên quan đến kết quả thực hiện thủ tục phân tích thành phần chính được tổng hợp ở Hình 6-7 và Bảng 8 . Chỉ số Eigenvalues đạt được với trị số cao [25, 26], ứng vớitrị số $1,287>1,0$. Tổng phương sai và phương sai tích lũy lần lượt các nhóm nhân tố với giá trị tương đương 12,875 và $86,426 \%$. So sánh kết với nghiên cứu của Rwoo et al.(2017) cho thấy các nhóm nhân tố trích xoay có mức độ giải thích thấp hơn, tương ứng trị tổng phương sai tích lũy đạt $62,86 \%$ [14].

Bảng 8. Ma trận trích xoay PCA chất lượng nước

\begin{tabular}{llll}
\hline \multirow{2}{*}{ Thông số } & \multicolumn{3}{l}{ Thành phần chính } \\
\cline { 2 - 4 } & PC-1 & PC-2 & PC-3 \\
\hline Pecmanganat & $\mathbf{0 , 9 3 3}$ & 0,102 & $-0,019$ \\
Màu sắc & $\mathbf{0 , 8 7 4}$ & 0,407 & $-0,027$ \\
Fe & $\mathbf{0 , 7 7 6}$ & 0,550 & 0,017 \\
Độ đục & $\mathbf{0 , 7 7 2}$ & 0,596 & 0,002 \\
pH & $\mathbf{0 , 5 2 7}$ & $-0,111$ & 0,385 \\
$\mathrm{NH}_{4}{ }^{+}$ & 0,040 & $\mathbf{0 , 9 0 4}$ & $-0,051$ \\
Flo & 0,383 & $\mathbf{0 , 8 4 8}$ & $-0,153$ \\
Coliform & 0,351 & $\mathbf{0 , 7 9 3}$ & 0,454 \\
Clo & $-0,041$ & $-0,179$ & $\mathbf{0 , 9 5 1}$ \\
Độ cứng & 0,044 & 0,203 & $\mathbf{0 , 9 4 2}$ \\
Đại diện biến & 5,209 & 2,146 & 1,287 \\
thiên & 52,086 & 21,465 & 12,875 \\
Phương sai, \% & 52,086 & 73,551 & 86,426 \\
Phương sai tích & 52,060 \\
lũy, \% & & & \\
\hline
\end{tabular}

Kết quả PCA trích xuất ba nhóm nhân tố chính (PCs) bao gồm: PC-1 gồm các thông số pecmaganat $(\mathrm{Pec})$, màu (color), sắt $(\mathrm{Fe})$, độ đục (Tur) và $\mathrm{pH}$. Hệ số tải trọng trong nhóm đạt mức cao, lần lượt tương ứng 0,$933 ; 0,874 ; 0,776$; 0,772 và 0,527 . Sự có mặt của độ đục chỉ thị các thành phần muối khoáng trong nguồn nước. Hệ số tải trọng cao của các chỉ tiêu chất lượng nước phần nào cho thấy tương quan với nguồn gốc và chất lượng nước cấp từ nước ngầm [16]. PC-2 bao gồm các thông số chất lượng nước như $\mathrm{NH}_{4}^{+}$, flo và chỉ tiêu coliform. Hàm lượng coliform chỉ thị cho sự nhiễm bẩn vi sinh và hàm lượng amoni chỉ thị vấn đề lo lắng liên quan đến sức khỏe con người. Thông thường, các mầm bệnh tiềm chứa trong nguồn nước gắn liền với việc đổ thải chất thải của con người [27]. Cấp độ flo trong nguồn nước thường được lý giải gắn liền với sự có mặt các loại khoáng chứa florua ở các khu vực khai thác nước ngầm [28]. Trong khi, PC-3 gồm hai thông số clo và độ cứng 
(Hard) với hệ số tải trọng đạt 0,951 và 0,942 . Hàm lượng clo trong nước có nguồn gốc từ tự nhiên cũng như từ các hoạt động chảy tràn, nước thải công nghiệp, sau đó thẩm thấu vào đất và đi vào các mạch nước ngầm [29]. Như vậy, kết quả phân tích PCA cho thấy mối tương quan chặt chẽ giữa các thông số chất lượng nước. Đồng thời, qua đó giải thích được các nhóm thành phần chính đánh giá chất lượng nước. Có thể thấy, kỹ thuật phân tích thống kê đa biến như phân tích tương quan và PCA được xem như là công cụ hữu ích giải thích tập dữ liệu các thông số chất lượng nước $[15,30]$.

\section{Kết luận}

Từ các kết quả nghiên cứu cho thấy hệ thống cung cấp nước sạch nông thôn trên địa bàn huyện Trảng Bàng chưa đảm bảo nhu cầu và chất lượng sử dụng của người dân. Tỷ lệ được cấp nước sạch chỉ mới đáp ứng $45,4 \%$ dân số. Về thực trạng chất lượng nước, các công trình cấp nước ở các xã Phước Chỉ, Phước Lưu và Bình Thạnh thuộc huyện Trảng Bàng có các thông số hóa lý thỏa mãn giới hạn cho phép của Quy chuẩn kỹ thuật quốc gia về nước sinh hoạt. Tuy nhiên, một số chỉ tiêu như vi sinh, độ đục, độ màu vượt ngưỡng cho phép của QCVN 01:2009/BYT của Bộ Y tế.

Quá trình phân tích thống kê đánh giá chất lượng nước cho thấy phần lớn các thông số chất lượng nước có mối liên hệ chặt chẽ có ý nghĩa thống kê $(\mathrm{p}<0,05)$. Kết quả PCA trích xuất ba nhóm nhân tố chính (PCs) bao gồm: PC-1 gồm các thông số pecmaganat (Pec), màu (color), sắt $(\mathrm{Fe})$, độ đục (Tur) và $\mathrm{pH}$. $\mathrm{PC}-2$ bao gồm các thông số chất lượng nước như $\mathrm{NH}_{4}{ }^{+}$, flo và chỉ tiêucoliform. PC-3 gồm hai thông số clo và độ cứng với hệ số tải trọng cao. PCA là công cụ hữu ích, sử dụng rộng rãi để nghiên cứu giải thích nguồn tác động đến tình trạng chất lượng nước. Qua đó, chỉ ra một số yếu tố có nguy cơ ảnh hưởng đến sức khỏe nếu như không có các biện pháp phòng tránh kịp thời. Do đó, nghiên cứu đề xuất một số giải pháp như cần phải rà soát hệ thống khử trùng nước cấp đầu ra đảm bảo yêu cầu quy định của QCVN 01:2009 BYT về tiêu chuẩn cấp nước cho ăn uống. Ngoài ra, cần rà soát và nâng cấp thiết bị lọc của các hệ thống cấp nước cũng như tiến hành công tác đào tạo nhân viên các trạm cấp nước chuẩn hóa quy trình vận hành và các kiến thức cơ bản bảo trì, tu sửa, ứng phó tình trạng sự cố khẩn cấp.

\section{Tài liệu tham khảo}

[1] Khan, N., Syed T.H., Javid H., Nargis J., Shabir A., Riaz U., Zain U., Abdus S., (2012). Physiochemical evaluation of the drinking water sources from district Kohat, Khyber Pukhtunkhwa, Pakistan. International Journal of Water Resources and Environmental Engineering, 4(10):302-313.

[2] World Health Organization (2011). Guidelines for Drinking-Water Quality, $4^{\text {th }}$ Edition.World Health Organization, Geneva.

[3] Bruning-Fann C.S., Kaneene J.B., (1993). The effects of nitrate, nitrite and N-nitroso compounds on human health. Vet Hum Toxicol, 35:521-538.

[4] Cantor K.P., (1997). Drinking water and cancer. Cancer Causes Control, 8:292-308.

[5] Jing Z., (2012). The impact of water quality on health: Evidence from the drinking water infrastructure program in rural China. Journal of Health Economics, 31(1):122-134.

[6] Ying Z., Xuemei H., Zhiguang N., (2018). Health risk assessment of haloacetonitriles in drinking water based on internal dose. Environmental Pollution, 236:899-906.

[7] Gleick, P.H. (Ed.). (1993). Water in Crisis: A Guide to the World's Fresh Water Resources. Oxford University Press, New York.

[8] WHO-UNICEF (2015). Progress on Sanitation and Drinking Water: 2015 Update and MDG Assessment. UNICEF Publisher, New York, US.

[9] Bartram, J., Cairncross, S., (2010). Hygiene, Sanitation, and Water: Forgotten Foundations of Health. PLoS Medicine, 7(11):e1000367.

[10] Cục thống kê tỉnh Tây Ninh (2017). Niên giám thống kê tỉnh Tây Ninh năm 2016. Tây Ninh.

[11] Boyacioglu H., (2006). Surface water quality assessment using factor analysis. Water SA, 32(3):389-393.

[12] Jolanta J., Elzbieta R., Katarzyna R., (2017). Principal Component Analysis And Cluster Analysis In Multivariate Assessment Of Water Quality. J. Ecol. Eng, 18(2):92-96. 
[13] Lianne M., Lalita B., Tasha E., Cheryl L.W.. (2017). Use of Principal Components Analysis and Kriging to Predict Groundwater-Sourced Rural Drinking Water Quality in Saskatchewan. Int. J. Environ. Res. Public Health, 14(9):1065-1089.

[14] Rwoo, M.A., H. Juahir, N.M. Roslan, A. Endut, M.K.A. Kamarudin, M.A. Amran., (2017). Assessment of drinking water quality using principal component analysis and partial least square discriminant analysis: A case study at water treatment plants, Selangor. J. Fundam. Appl. Sci., 9(2S):157-173.

[15] Simeonov V., Stratis J.A., Samara C., Zachariadis G., Voutsa D., Anthemidis A., Sofoniou M., Kouimtzis T., (2003). Assessment of the surface water quality in Northern Greece. Water Research, 37(17):4119-4124.

[16] Shyu, G.S., Cheng, B.Y., Chiang, C.T., Yao, P. H., Chang, T. K., (2011). Applying factor analysis combined withkriging and information entropy theory for mapping and evaluating the stability of groundwater quality variation in Taiwan. Int. J. Environ. Res. Public Health. 8:1084-1109.

[17] Yang C.Y., Cheng M.F., Tsai S.S., Hsieh Y.L., (1998). Calcium, Magnesium, and Nitrate in Drinking Water and Gastric Cancer Mortality. Jpn J Cancer Res, 89:124-130.

[18] EPA (2008).State of the Environment Report.Environmental Protection Agency, Wexford, Ireland.

[19] Cheng L.J.Y., Oh K.S., Poh P.E., Chong M.N., (2017). Prospects of hybrid rainwater-greywater decentralised system for water recycling and reuse: A review. Journal of Cleaner Production, 142(4):3014-3027.

[20] Sinha D.K., Rastogi G.K., Kumar R., Kumar N., (2009). Correlation study among water quality parameters an approach to water quality management. J Environ Sci Eng., 51(2):111-114.

[21] American Water Works Association (1999). Water Quality and Treatment. McGraw-Hill, Inc., New York, USA.
[22] World Health Organization (1996). Ammonia in Drinking-water: Guidelines for drinking-water quality $\left(2^{\text {nd }} \mathrm{Ed}\right)$. Geneva, Switzerland.

[23] Belkhiri, L., Boudoukha, A., Mouni, L., (2011). A multivariate statistical analysis of groundwater chemistry data. Int. J. Environ. Res., 5:537-544.

[24] Chapagain, S.K., Pandey, V.P., Shrestha, S., Nakamura, T., Kazama, F., (2010). Assessment of deep groundwater quality in Kathmandu Valley using multivariate statistical techniques. Water. Air. Soil Pollut., 210:277-288.

[25] Amadi, A.N., (2012). Quality Assessment of Aba River using heavy metal pollution index. American Journal of Environmental Enginerring, 2(1):45-49.

[26] Kaiser, H.F., (1960). The application of electronic computers to factor analysis. Educ. Psychol. Meas., 20:141-151.

[27] Osei J., Nyame F.K., Armah T.K., Osae S.K., Dampare S.B., Fianko J.R., Adomako D., Bentil N., (2012). Application of multivariate analysis for identification of pollution sources in the Densu Delta Wetland in the vicinity of a landfill site in Ghana. Journal of Water Resource and Protection, 2(12):1020-1029.

[28] Alagumuthu G., and Rajan M., (2010). Chemometric studies of water quality parameters of Sankarankovil block of Tirunelveli, Tamilnadu. Journal of Environmental Biology, 31(5):581-586.

[29] Mohammad A., Miri M., Ebrahimi A., Khorsandi H., Nemati S., (2016). Monitoring of THMs concentration in Isfahan water distribution system and zoning by GIS, a case study in the Centre of Iran. Iranian Journal of Health, Safety and Environment, 3(1):421-427.

[30] Ky N.M., Lam N.H., (2014). Using multivariate statistical techniques to assess water quality of Nhu $\mathrm{Y}$ river in Thua Thien Hue province. Journal ofScience \& Technology Development, 17(M1):50-60. 


\title{
Research on Status of Water Use and Quality of Domestic Supply Water in Trang Bang District, Tay Ninh Province
}

\author{
Nguyen Tri Quang Hung ${ }^{1}$, Dinh Hung Danh ${ }^{1}$, Thai Phuong Vu², \\ Nguyen Minh Ky ${ }^{1}$, Huynh Ngoc Anh Tuan ${ }^{1}$ \\ ${ }^{1}$ Nong Lam University of Ho Chi Minh City, Vietnam \\ ${ }^{2}$ Ho Chi Minh University of Natural Resources and Environment, Vietnam
}

\begin{abstract}
This paper presents the results of status of water use and quality of domestic water supplies in Trang Bang district, Tay Ninh province. Ratio of the local population could be accessed the safe drinking water in Trang Bang district which recording of low frequency. The study was conducted the sampling and evaluation of water quality in nine rural water supply stations in Phuoc Chi, Binh Thanh and Phuoc Luu communes, Trang Bang district. Analyzing results of the important water quality parameters at the rural water supply stations in Trang Bang district showed that these parameters met requirements National Technical Regulation on domestic water quality QCVN 02:2009/BYT and drinking water quality QCVN 01:2009/BYT. However, some monitoring samples ofE.coli level did not meet the water supply requirements for domestic and drinking purposes. Correlation coefficients among water quality parameters illustrated the strongly relationships at statistically significant $(\mathrm{p}<0.05)$. Results of PCA showed three principal components (PCs) with obtainable eigen values was equal to 1.287 and total cumulative variance within $86.426 \%$. It means the studying results could be used to assessing and interpreting of domestic supply water quality status in Trang bang district, Tay Ninh province.
\end{abstract}

Keywords: Water quality, Trang Bang, domestic, drinking water, water supply. 